\title{
DETERMINAN KINERJA USAHA MIKRO (STUDI PADA USAHA MIKRO DI KECAMATAN \\ WENANG, MANADO)
}

\author{
Paskanova Christi Gainau \\ Program Studi Akuntansi \\ STIE Eben Haezar Manado \\ paskanovagainau@stiebenzar.ac.id
}

\begin{abstract}
Nowadays, regarding increasing number of micro-business in urban areas, achieving competitive advantage is considered as one of the business concerns. Obtaining competitive advantage entails specific requirements that social capital, physical capital, and human capital - is regarded as one of the most important factors. This study aims to examine the effect of capital to the performance of microbusinesses. The sample of this study was 31 micro-businesses in Wenang subdistrict, Manado, who were selected by simple random sampling. After distributing the questionnaires, the data analysis was done by SmartPLS 3.0 M3. The result show that social capital and physical capital had no significant effect on the performance of micro-business, while human capital had a positive, and significant effect on the business performance. The implication is the Manado City government has to make the labor of micro-business as the target of empowerment activities that are organized by the government, private sector, bank, NGOs, domestic or foreign. In the long term, it can drive the micro-industry to the small and medium industries.
\end{abstract}

Keywords: human capital, social capital, physical capital, micro-business performance.

\begin{abstract}
ABSTRAK
Saat ini, sehubungan dengan meningkatnya jumlah bisnis mikro di daerah perkotaan, mencapai keunggulan kompetitif dianggap sebagai salah satu fokus bisnis. Mencapai keunggulan kompetitif memerlukan persyaratan khusus seperti modal sosial, modal fisik, dan modal manusia, yang dianggap sebagai faktor paling penting. Penelitian ini bertujuan mengkaji sejauh mana kontribusi modal terhadap kinerja usaha mikro di Kecamatan Wenang, Kota Manado. Sampel penelitian ini adalah 31 usaha mikro di pusat kota Manado yang dipilih secara acak. Setelah mendistribusikan kuesioner dan mengumpulkannya, analisis data dilakukan oleh SmartPLS 3.0 M3. Hasil kajian menemukan bahwa modal sosial dan modal fisik tidak berpengaruh terhadap kinerja usaha mikro, sedangkan modal sumber daya manusia berpengaruh positif terhadap kinerja usaha mikro. Implikasi terapannya
\end{abstract}


adalah pemerintah Kota Manado sangat perlu menjadikan tenaga kerja industri mikro sebagai kelompok sasaran dalam kegiatan pemberdayaan yang diselenggarakan oleh pihak pemerintah, swasta, bank, LSM, dalam negeri maupun asing. Pemberdayaan ini penting karena dalam jangka panjang dapat menggerakkan industri mikro menuju industri kecil dan menengah.

Kata kunci: modal manusia, modal sosial, modal fisik, performa bisnis mikro.

\section{PENDAHULUAN}

Gerak Usaha Mikro dan Kecil (UMK) telah berdampak pada sebagian besar hidup masyarakat, salah satunya melalui penyediaan kesempatan kerja sebesar 97,2\% (Wilantara dan Susilawati, 2016: 13). Secara khusus, di Sulawesi Utara, sektor Usaha Mikro dan Kecil (UMK) telah menyerap 640.000 tenaga kerja. Jumlah dan persentase UMK terbanyak berada di Kota Manado dengan jumlah 60.961 usaha (20,87\%) (Bidang Neraca Wilayah dan Analis Statistik, 2016). Gambar 1 menunjukkan grafik tenga kerja industri mikro di Sulawesi Utara.

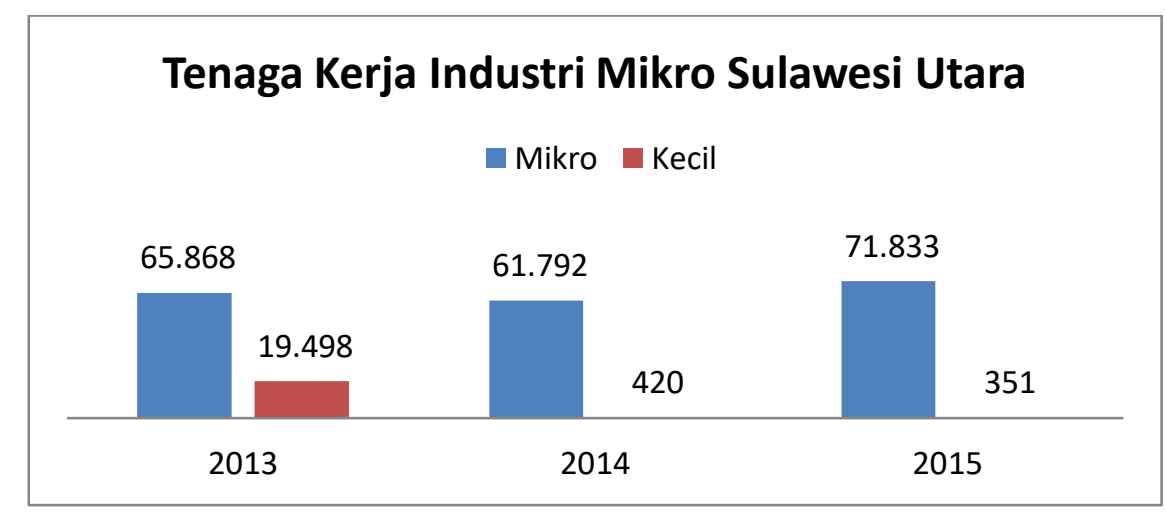

Gambar 1

Data Tenaga Kerja Industri Mikro Sulawesi Utara

Sumber: BPS Sulawesi Utara

Gambar 1 memperlihatkan bahwa jumlah tenaga kerja pada industri mikro cenderung meningkat dibanding industri kecil. Selain itu, besaran angka industri mikro ini tidaklah jauh berbeda dari tahun ke tahun. Hal ini berarti kinerja usaha mikro tidak mengalami peningkatan yang signifikan menuju level industri kecil atau menengah. Beberapa penelitian menemukan permasalahan yang dihadapi UMK antara lain sumber daya manusia (Dewi, 2013; Purwaningsih dan Kusuma, 2015; Sandra dan Purwanto, 2017; Saddam dan Mahfudz, 2017), teknik produk, keuangan (Purwaningsih dan Kusuma, 2015), pemasaran, dan akses pasar yang luas (Santoso et al., 2015).

Hmieleski and Corbett (2006), dan Analia et al. (2019) menemukan bahwa kinerja usaha bergantung signifikan pada improvisasi yang dilakukan. Usaha yang tidak melakukan improvisasi akan sulit mengalami pertumbuhan kinerja. 
Improvisasi tentu harus didukung oleh struktur modal (Saddam dan Mahfudz, 2017) dan SDM (sumber daya manusia) yang berkualitas. SDM yang berkualitas merujuk pada hardskill maupun softskill yang memadai. Kombinasi modal, hardskill, dan softskill mendorong dilakukannya improvisasi yang pada akhirnya mendorong peningkatan kinerja usaha. Hal ini searah dengan hasil penelitian Sandra dan Purwanto (2017) yang menemukan bahwa modal manusia berpengaruh signifikan terhadap kinerja usaha mikro dan kecil. Namun fakta menunjukkan bahwa modal manusia (keterampilan) pada UMK masih terbatas sehingga menghambat inovasi.

Improvisasi tidak dapat dilakukan tanpa ketersediaan modal fisik yang memadai. Modal fisik merujuk pada aset-aset fisik yang digunakan dalam teknik produksi sehari-hari. Sandra dan Purwanto (2017), Mahesa et al. (2016) menemukan bahwa ketersediaan modal fisik mampu mendongkrak kinerja usaha. Wauran (2012) juga menemukan bahwa permasalahan utama para pedagang sektor mikro adalah keterbatasan akses ke lembaga keuangan formal untuk mendapatkan kredit usaha. Selain itu, ada ketidakpercayaan diri bila berhadapan dengan pihak perbankan sehubungan dengan pendidikan mereka yang rendah, padahal pendapatan UMK sangat bagus untuk mendapatkan kredit.

Kinerja usaha juga ditentukan oleh modal sosial yang dimiliki (Schenkel et al., 2012; Primadona dan Emrizal, 2017; Worokinasih and Potipiroon, 2019). Modal sosial mengacu pada dukungan dan kepercayaan dari pihak lain di dalam lingkungan usaha, seperti pelanggan, pemasok, kreditur, dan pemerintah. Purwaningsih dan Kusuma (2015) menemukan bahwa kebijakan pemerintah, kondisi sosial, dan peranan lembaga lain turut memberi pengaruh yang signifikan pada kondisi internal UMK.

Era digital 4.0 telah menggeserkan sistem ekonomi rakyat ke ekonomi modern. Sebagian usaha mulai menerapkan teknologi informasi dalam teknik produksi sampai teknik pemasarannya yang mengutamakan efisiensi waktu dan tenaga. Dutot and Bergeron dalam Imran and Jian (2018) menegaskan 30 juta pelaku UMKM merupakan pengguna aktif sosial media.

Namun, tak dapat dipungkiri bahwa masih ada UMK yang tetap menganut sistem ekonomi kerakyatan yang berlandaskan rasa saling percaya antara pelaku usaha dengan lingkungannya. Kemajuan UMK dipengaruhi oleh dukungan keluarga (Suriantna dan Ardianti, 2013), kreditur, dan pelanggan (Worokinasih and Potipiroon, 2019). De Oliveira (2013) dan Analia et al., (2019) menegaskan relasi dengan pihak lain (network) tersebut mendukung usaha untuk mengakses informasi. Namun, modal kepercayaan saja tidak cukup untuk mendongkrak kinerja UMK karena UMK juga membutuhkan sumber daya fisik (peralatan, teknologi, dan kelengkapannya) dan SDM yang kompeten. Penelitian ini bertujuan untuk menguji pengaruh modal manusia, modal fisik, dan modal sosial terhadap kinerja UMK.

\section{TINJAUAN PUSTAKA}

\section{Teori Resource Based}

Teori Resources Based mengacu pada sumber daya yang dibutuhkan oleh organisasi untuk mencapai keunggulan kompetitif. Menurut Barney (2001), sumber daya merupakan keseluruhan aset (tangible dan intangible), atribut perusahaan (reputasi dan inovasi), informasi, kemampuan, dan strategi mengelola sumber daya 
yang dapat meningkatkan efektivitas dan efisiensi perusahaan. Tangible asset merupakan aset fisik yang dapat dilihat dan disentuh, seperti tanah, gedung, peralatan. Intangible asset terdiri dari SDM (pekerja terampil, berpengalaman, kreatif, pemecah masalah) dan sumber daya intelektual (kualitas produk/brand, patent, dan partnership).

Model Resources Based merupakan model yang tepat untuk menganalisis sumber daya dari sebuah perusahaan untuk mencapai keunggulan kompetitif. Model ini mengandung aspek Valuable, Rare, Imitable, dan exploited in Organization yang disingkat VRIO. Untuk mencapai keunggulan kompetitif sebuah perusahaan perlu mengombinasikan keempat kerangka VRIO di atas. Hal tersebut berkaitan dengan sumber daya, kinerja, dan manajemen (Barney, 2001). Grant (1991) mengembangkan enam kategori sumber daya perusahaan yang menunjang pertumbuhan sebuah usaha, antara lain: sumber daya keuangan (financial resources), sumber daya fisik (physical resources), sumber daya manusia (human resources), sumber daya teknologi (technological resources), reputasi (reputation), sumber daya organisasi (organizational resources).

Penelitian saat ini mengkaji sumber daya manusia (modal manusia), sumber daya fisik (modal fisik), dan modal sosial. Chittithaworn et al. (2011) menemukan lima faktor penting bagi keberhasilan UMKM yaitu karyawan, pelanggan, strategi bisnis, keuangan, dan sumber daya, serta lingkungan luar.

\section{HIPOTESIS PENELITIAN \\ Pengembangan Hipotesis \\ Modal Sumber Daya Manusia dan Kinerja Usaha Mikro}

Menurut teori modal manusia, individu yang memiliki keterampilan, kemampuan, dan pengetahuan adalah individu yang memberikan nilai ekonomi bagi perusahaan (Sáez et al., 2006). Modal SDM merujuk pada hardskill (pendidikan) dan softskill yang dimiliki. Grant (1991) memandang modal SDM sebagai masukan bagi proses produksi yang ditunjukkan dalam keterampilan karyawan, patent, dan brand.

Schenkel et al. (2012) menyatakan modal SDM berkaitan dengan aspek keterampilan, wawasan, dan motivasi. Fungsi dari aspek-aspek ini akan berdampak signifikan dalam suatu proses bisnis. Outcome yang dihasilkan oleh sebuah usaha dipengaruhi oleh modal manusianya, seperti pengetahuan (Diochon et al., 2008), keterampilan karyawan (Sandra, dan Purwanto, 2017), dan motivasi individu (Hmieleski, and Corbett, 2006; Cardon et al., 2009). Pendidikan formal menyediakan keterampilan dan kualitas khusus bagi seorang pelaku usaha.

Ada tiga jenis modal manusia yang secara sistematis dapat mempengaruhi masa depan sebuah bisnis. Pertama, pengetahuan eksplisit (explicit knowledge), di mana hal ini mengacu pada aspek informasi yang diartikulasikan dalam bahasa simbolik yang formal (Polanyi dalam Schenkel et al., 2012). Pengetahuan eksplisit ini diperoleh melalui proses pendidikan dan pelatihan formal. Aspek pendidikan (Gonzalez-Uribe, and Leatherbee, 2018) dan pemberdayaan UMKM (Samosir et al., 2016) berpengaruh terhadap kinerja usaha mikro. Kedua, pengetahuan tacit (tacit knowledge), di mana mengacu pada aspek spesifik dari informasi yang sulit diartikulasikan atau ditransmisikan secara formal misalnya, pengetahuan tentang 
pasar, pelanggan, teknologi, pengalaman kerja, dan pengalaman kepemimpinan. Hasil penelitian Wu and Chen (2014) menemukan bahwa pengetahuan, pengalaman kerja, dan pengalaman kepemimpinan turut mendorong proses menciptakan nilai tambah bagi usaha. Ketiga, motivasi pemrosesan informasi (information processing motivation), di mana hal ini mengacu pada motivasi seseorang untuk memproses informasi baru demi mendukung pengambilan keputusan bisnis. Era digital 4.0 ini menuntut SDM yang menguasai teknologi dan informasi dengan baik. Pelaku usaha yang tidak menguasai bidang ini tidak akan produktif karena kehilangan pelanggan.

Penelitian Dewi (2013), Purwaningsih dan Kusuma (2015), Sandra dan Purwanto (2017), Saddam dan Mahfudz (2017) menemukan bahwa modal SDM berpengaruh signifikan terhadap kinerja usaha mikro dan kecil. Dimensi yang dianalisis adalah tingkat pendidikan, kesehatan, keahlian, pengalaman, karakter, dan spiritualitas. Investasi di bidang pendidikan berdampak positif pada kualitas SDM (Hasan and Abdullah, 2018). Pelaku usaha mikro sangat membutuhkan pendidikan, pelatihan, dan pemberdayaan secara berkelanjutan agar mendorong peningkatan produktivitas sehingga dalam jangka panjang omzet meningkat dan usaha dapat meningkat ke level industri kecil dan menengah. Berdasarkan ulasan di atas maka dirumuskanlah hipotesis sebagai berikut:

$\mathrm{H}_{1}$ : Modal Sumber Daya Manusia berpengaruh signifikan terhadap Kinerja Usaha Mikro.

\section{Modal Fisik dan Kinerja Usaha Mikro}

Modal fisik merujuk pada aset-aset fisik yang digunakan dalam aktivitas bisnis sehari-hari. Modal ini terdiri dari barang-barang buatan manusia yang membantu jalannya proses produksi. Grant (1991) menyebut modal fisik sebagai sumber daya input yang diperlukan dalam proses produksi. Hal ini berarti modal fisik memiliki peran penting bagi kinerja sebuah usaha di mana tanpa sumber daya ini sebuah usaha tak dapat menghasilkan produk. Modal fisik dapat berupa peralatan, perlengkapan, bahan baku, mesin, kendaraan, gedung, dan tanah. Ketersediaan modal fisik yang memadai mampu mendongkrak kinerja usaha (Mahesa et al., 2016; Prasetyo dan Harjanti, 2013). Grant (1991) menyatakan perusahaan yang mengetahui cara mengelola sumber daya fisiknya dengan baik akan mencapai keunggulan kompetitif.

Pelaku usaha mikro mengombinasikan modal fisik yang sederhana dengan proses manual untuk menghasilkan produk. Pola ini tentu mempengaruhi produktivitas yang dicapai. Beberapa hasil penelitian telah membuktikan bahwa modal fisik melalui teknik produksi (Sandra dan Purwanto, 2017; Purwaningsih dan Kusuma, 2015) berpengaruh signifikan terhadap keberhasilan usaha mikro, kecil dan menengah.

Usaha mikro cenderung menghasilkan produk secara stabil. Pada musimmusim tertentu pelaku usaha akan memproduksi di atas rata-rata, misalnya musim liburan, weekend, musim pegawai negeri/swasta menerima gaji, dan hari besar lainnya. Musim ini akan memicu pelaku usaha untuk berproduksi di atas rata-rata. Mengingat jumlah usaha mikro yang sangat banyak, maka sangat penting untuk mengupayakan peningkatan produktivitas usaha mikro. Salah satu caranya adalah mengindentifikasi kemampuan modal fisiknya dan memanfaatkannya dengan baik 
untuk menghasilkan produk (Grant, 1991). Hal ini dimaksudkan agar dalam jangka menengah dan jangka panjang, kinerja usaha mikro dapat meningkat. Berdasarkan ulasan di atas, maka dapat dirumuskan hipotesis sebagai berikut:

$\mathrm{H}_{2}$ : Modal fisik berpengaruh signifikan terhadap kinerja usaha mikro.

\section{Modal Sosial dan Kinerja Usaha Mikro}

Modal sosial mengacu pada norma, hubungan (network), dan kepercayaan (trust) dari lingkungan terhadap suatu usaha (Steiner and Wang, 2016; Sandra dan Purwanto, 2017). Pada era konvensional, banyak usaha mikro yang bertahan karena modal sosialnya. Pelaku usaha membangun relasi dengan lingkungan demi mempertahankan usahanya. Setyawan et al. (2019) menyatakan bahwa komponen dasar dalam hubungan berbisnis adalah kepercayaan (trust). Modal sosial telah menjadi bagian integral dari pertumbuhan usaha (Primadona dan Emrizal, 2017; Pierre, 2017), keberhasilan wirausahawan (Schenkel et al., 2012), dan pertumbuhan ekonomi (Thobias et al., 2013).

Secara spesifik, hubungan yang erat dengan keluarga dan teman berdampak positif terhadap usaha karena di dalamnya mengandung dimensi kepercayaan yang kuat (Binarto, 2013). Investasi dalam hubungan sosial menciptakan goodwill bagi sebuah usaha. Studi Schenkel et al., (2012), Steiner and Wang (2016), dan Primadona dan Emrizal (2017) menemukan bahwa modal sosial mempengaruhi kinerja UMK. Alasannya, hubungan sosial yang terbangun dapat menciptakan jaringan kerja horizontal dengan pihak-pihak yang lebih tinggi untuk mengakses informasi yang relevan bagi usaha (De Oliveira, 2013). Namun, Prasetyo dan Harjanti (2013) menemukan modal sosial tidak berhubungan dengan kinerja usaha. Mengingat setiap usaha membutuhkan unsur kepercayaan dari para pemangku kepentingan demi keberlanjutan usahanya, maka dirumuskanlah hipotesis sebagai berikut:

$\mathrm{H}_{3}$ : Modal sosial berpengaruh signifikan terhadap kinerja usaha mikro

\section{METODE PENELITIAN}

Jenis dan Sumber Data

Penelitian ini menggunakan data primer yang bersumber dari observasi, wawancara, dan pengisian kuesioner oleh pelaku industri manufaktur mikro di pusat Kota Manado. Kuesioner ini dikembangkan oleh peneliti.

\section{Populasi, Sampel, dan Teknik Pengambilan Sampel}

Populasi dalam penelitian ini adalah seluruh pelaku industri manufaktur mikro di Kecamatan Wenang. Alasan memilih Kecamatan Wenang adalah karena kecamatan ini meliputi area pusat Kota Manado (center of the city). Pengambilan sampel didasarkan pada metode accidental sampling. Sampel yang berhasil diperoleh adalah 31 pengusaha mikro yang berbisnis di Kecamatan Wenang, pusat Kota Manado. 


\section{Definisi dan Pengukuran Variabel}

Variabel yang digunakan, definisi, dan indikator yang digunakan untuk mengukur masing-masing variabel seperti terlihat pada Tabel 1 .

Tabel 1

Definisi Operasional dan Pengukuran Variabel

\begin{tabular}{|c|c|c|}
\hline Variabel & Definisi & Indikator \\
\hline $\begin{array}{c}\text { Modal } \\
\text { SDM } \\
\text { (MSDM) }\end{array}$ & $\begin{array}{l}\text { Pengetahuan, keterampilan, } \\
\text { kemampuan, pengalaman, dan } \\
\text { keahlian karyawan yang digunakan } \\
\text { untuk mencapai keunggulan } \\
\text { kompetitif (Wu and Chen, 2014). }\end{array}$ & $\begin{array}{l}\text { Mengeyam pendidikan formal minimal SMA. } \\
\text { Mampu melakukan inovasi. } \\
\text { Menguasai teknologi. } \\
\text { Mampu menciptakan produk berkualitas. } \\
\text { Memiliki keterampilan memproduksi barang. } \\
\text { Memiliki kesehatan yang baik. }\end{array}$ \\
\hline $\begin{array}{l}\text { Modal } \\
\text { Fisik } \\
\text { (MF) }\end{array}$ & $\begin{array}{l}\text { Sumber daya input yang ditampilkan } \\
\text { melalui ketersediaan aset lancar dan } \\
\text { aset tetap untuk mendukung proses } \\
\text { produksi (Grant,1991). }\end{array}$ & $\begin{array}{c}\text { Ketersediaan uang. } \\
\text { Ketersediaan bahan baku. } \\
\text { Ketersediaan mesin/peralatan. } \\
\text { Ketersediaan Gedung. } \\
\text { Ketersediaan lahan. }\end{array}$ \\
\hline $\begin{array}{l}\text { Modal } \\
\text { Sosial } \\
\text { (MS) }\end{array}$ & $\begin{array}{c}\text { Hubungan antar manusia yang } \\
\text { ditopang oleh jaringan, norma-norma, } \\
\text { dan kepercayaan sosial yang } \\
\text { memungkinkan efisiensi dan } \\
\text { efektifitas kerjasama untuk mencapai } \\
\text { keuntungan bersama (Cox dalam } \\
\text { (Primadona dan Emrizal, 2017). }\end{array}$ & $\begin{array}{l}\text { Jaringan. } \\
\text { Norma Sosial. } \\
\text { Kepercayaan. } \\
\text { Resiprositas. } \\
\text { Nilai. } \\
\text { Kerjasama. }\end{array}$ \\
\hline $\begin{array}{l}\text { Kinerja } \\
\text { Usaha } \\
\text { Mikro } \\
\text { (KUM) }\end{array}$ & $\begin{array}{l}\text { Deskripsi hasil kerja yang telah } \\
\text { dicapai melalui rangkaian aktivitas } \\
\text { tertentu pada akhir periode bisnis } \\
\text { (Ramaseshan et al., 2006). }\end{array}$ & $\begin{array}{c}\text { Peningkatan penjualan. } \\
\text { Peningkatan modal. } \\
\text { Penambahan tenaga kerja setiap tahun. } \\
\text { Pertumbuhan pangsa pasar. } \\
\text { Peningkatan keuntungan (laba bersih). }\end{array}$ \\
\hline
\end{tabular}

Sedangkan kerangka model penelitian yang dipakai dalam penelitian ini seperti terlihat pada Gambar 2 di bawah ini.

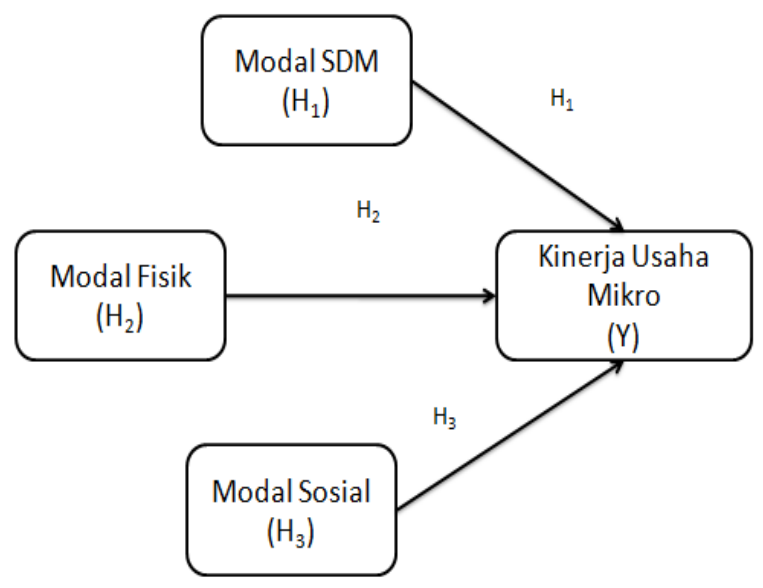

Gambar 2

Kerangka Model Penelitian 


\section{Teknik Analisis Data}

Pengujian hipotesis dilakukan dengan alat analisis Partial Least Square (PLS). PLS adalah salah satu metode statistika SEM berbasis varian yang didesain untuk menyelesaikan regresi berganda ketika terjadi permasalahan spesifik pada data, seperti ukuran sampel penelitian kecil, adanya data yang hilang (missing value), dan multikolinearilitas (Latan, dan Ghozali, 2012). Uji yang dilakukan dalam penelitian ini adalah: a) uji kecocokan model pengukuran (outer model) yang dilakukan melalui uji validitas dan reliabilitas, b) uji kecocokan model struktural (inner model) yang dilakukan melalui kekuatan prediksi yang dilihat dari nilai $R$ Squares dan uji hipotesis yang dilihat dari nilai t-statistic, c) uji kecocokan model keseluruhan (overall fit index) yang dilakukan dengan menggunakan kriteria goodness of fit yang dikembangkan oleh Tenenhaus et al. (2004) dengan sebutan GoF index. Indeks ini dikembangkan untuk mengevaluasi tingkat kesesuaian model secara keseluruhan. Untuk alasan ini GoF index dihitung dari akar kuadrat nilai average communality index dan average $R$-squares:

$$
\mathrm{GoF}=\sqrt{\operatorname{Com} \times \mathrm{R}^{2}}
$$

Nilai communality yang direkomendasikan adalah 0,50 (Fornell and Larcker dalam Latan dan Ghozali, 2012), sehingga hasil perhitungan untuk standar nilai GoF index kecil, sedang, dan besar adalah 0,1, 0,25, dan 0,36. Angka ini mengisyaratkan bahwa model yang diuji memiliki kesesuaian kecil, sedang, dan besar (Ghozali dan Fuad, 2008).

\section{HASIL DAN PEMBAHASAN Karakteristik Responden}

Karakteristik dari 31 responden usaha mikro yang diamati dalam penelitian ini meliputi jenis kelamin, usia, pendidikan terakhir, bidang usaha, dan lama usaha. Pelaku usaha mikro laki-laki sama banyaknya dengan pelaku usaha mikro perempuan, di mana sebagian besar berasal dari golongan usia 40 - 60 tahun dengan tingkat pendidikan formalnya adalah SLA/SMA/SMK (50\%). Bidang usaha yang paling banyak diminati adalah kuliner (93\%). Tingkat konsumsi masyarakat Manado yang sangat tinggi membuat usaha kuliner bertumbuh pesat di kota ini. Rata-rata lama berusaha adalah lebih dari lima (5) tahun.

Tabel 2

Data Demografi Responden

\begin{tabular}{cccc}
\hline \multicolumn{2}{c}{ Demografi Responden } & Jumlah & Persentase \\
\hline \multirow{2}{*}{ Jenis Kelamin } & Laki-laki & 16 & $52 \%$ \\
& Perempuan & 15 & $48 \%$ \\
\multirow{2}{*}{ Usia } & $19-39$ tahun & 10 & $32 \%$ \\
& $40-60$ tahun & 17 & $55 \%$ \\
& $61-73$ tahun & 4 & $13 \%$ \\
\hline
\end{tabular}




\begin{tabular}{cccc}
\hline & SR/SD & 6 & $19 \%$ \\
Pendidikan Terakhir & SMP & 6 & $19 \%$ \\
& SLA/ SMA / SMK & 15 & $48 \%$ \\
& S1 & 3 & $10 \%$ \\
Bidang Usaha & S2 & 1 & $1 \%$ \\
& Kuliner \& Dagang & 29 & $94 \%$ \\
Lama Usaha & Percetakan & 2 & $6 \%$ \\
& $<2$ tahun & 5 & $16 \%$ \\
\multirow{3}{*}{ Omzet per Bulan } & $2-5$ tahun & 10 & $32 \%$ \\
& $>5$ tahun & 16 & $52 \%$ \\
& $<$ Rp 5.000.000,- & 15 & $48 \%$ \\
& Rp 5.000.000 - Rp 10.000.000,- & 4 & $13 \%$ \\
& $>$ Rp 10.000.000,- & 12 & $39 \%$ \\
\hline
\end{tabular}

\section{Hasil Pengujian}

Berikut ini disajikan hasil pengujian awal terhadap indikator konstruk. Indikator yang tidak valid tidak akan diikutsertakan dalam pengujian hipotesis.

Tabel 3

Uji Validitas Indikator (Awal)

\begin{tabular}{c|cccc}
\hline Variabel & Indikator & $\begin{array}{c}\text { Load Factor } \\
>0,50\end{array}$ & AVE & Validitas \\
\hline \multirow{5}{*}{ Modal Sosial } & MS1 & 0,587 & & Valid \\
& MS2 & 0,494 & & Tidak Valid \\
& MS3 & 0,757 & & Valid \\
& MS4 & 0,568 & 0,194 & Valid \\
& MS5 & $-0,079$ & & Tidak Valid \\
& MS6 & $-0,480$ & & Tidak Valid \\
& MS7 & $-0,217$ & & Tidak Valid \\
& MS8 & 0,636 & & Valid \\
\hline \multirow{5}{*}{ Modal Fisik } & MF1 & 0,751 & & Valid \\
& MF2 & 0,718 & & Valid \\
& MF3 & 0,712 & & Valid \\
& MF4 & 0,336 & & Tidak Valid \\
& MF5 & $-0,176$ & 0,704 & Tidak Valid \\
& MF6 & 0,456 & & Tidak Valid \\
& MF7 & 0,342 & & Tidak Valid \\
& MF8 & 0,353 & & Tidak Valid \\
& MF9 & 0,451 & & Tidak Valid \\
& MF10 & 0,481 & & Tidak Valid \\
\hline \multirow{5}{*}{ Modal Sumber } & MSDM1 & $-0,217$ & & Tidak Valid \\
Daya Manusia & MSDM2 & 0,433 & & Tidak Valid \\
& MSDM3 & 0,226 & & Tidak Valid \\
& MSDM4 & 0,060 & \multirow{2}{*}{0,522} & Tidak Valid \\
& MSDM5 & $-0,259$ & & Tidak Valid \\
& MSDM6 & 0,727 & & Valid \\
& MSDM7 & 0,773 & & Valid \\
& MSDM8 & 0,583 & & Valid \\
\hline \multirow{5}{*}{ Kinerja Usaha } & KUM1 & 0,701 & & Valid \\
& KUM2 & 0,292 & & Tidak Valid \\
& KUM3 & 0,067 & 0,502 & Tidak Valid \\
& KUM4 & 0,748 & & Valid \\
& KUM5 & 0,825 & & Valid \\
\hline
\end{tabular}


Hasil uji validitas dari output SmartPLS 3.0 M3 setelah beberapa indikator dihilangkan menunjukkan bahwa semua indikator dinyatakan valid. Hal ini seperti terlihat pada Tabel 4.

Tabel 4

Uji Validitas Indikator

\begin{tabular}{ccccc}
\hline Variabel & Indikator & $\begin{array}{c}\text { Load Factor } \\
>0,50\end{array}$ & AVE & Validitas \\
\hline Modal & MS1 & 0,867 & & Valid \\
Sosial & MS4 & 0,846 & 0,734 & Valid \\
& MS8 & 0,568 & & Valid \\
Modal & MF1 & 0,636 & & Valid \\
Fisik & MF2 & 0,845 & 0,705 & Valid \\
& MF3 & 0,800 & & Valid \\
Modal & MSDM6 & 0,690 & & Valid \\
SDM & MSDM7 & 0,837 & 0,503 & Valid \\
& MSDM8 & 0,577 & & Valid \\
Kinerja & KUM1 & 0,630 & & Valid \\
Usaha & KUM4 & 0,830 & \multirow{2}{*}{0,584} & Valid \\
Mikro & KUM5 & 0,816 & & Valid \\
\hline
\end{tabular}

Tahapan kedua adalah pengujian model kecocokan pengukuran yang dilakukan terhadap masing-masing konstruk laten telah valid. Pemeriksaan terhadap konstruk laten dilakukan terkait dengan pengukuran konstruk laten oleh variabel manifest (indikator). Melalui program SmartPLS 2.0 M3, pengukuran reliabilitas konstruk dengan indikator refleksif yang tampak dari nilai composite reliability dan cronbach's alpha. Nilai composite reliability dan cronbach's alpha harus lebih besar dari 0,70 (Latan, dan Ghozali, 2012).

Tabel 5

Hasil Uji Reliabilitas

\begin{tabular}{cccc}
\hline $\begin{array}{c}\text { Variabel } \\
\text { Laten }\end{array}$ & $\begin{array}{c}\text { Composite Reliability } \\
\geq 0,70\end{array}$ & $\begin{array}{c}\text { Cronbach's } \\
\text { Alpha }\end{array}$ & Kesimpulan \\
\hline Modal Sosial & 0,846 & 0,637 & Reliabel \\
Modal Fisik & 0,877 & 0,803 & Reliabel \\
Modal SDM & 0,748 & 0,503 & Reliabel \\
Kinerja Usaha Mikro & 0,806 & 0,679 & Reliabel \\
\hline
\end{tabular}

Hasil pengujian menunjukkan bahwa keempat variabel yang digunakan dalam penelitian ini dinyatakan reliabel. 


\section{Kecocokan Model Struktural (Inner Model)}

Dalam menilai model struktural dengan PLS, dimulai dengan menilai $R$-Square untuk setiap variabel laten endogen sebagai kekuatan prediksi dari model struktural. Nilai $R$-Square 0,75, 0,50, dan 0,25 menunjukkan bahwa model kuat, moderate dan lemah yang merepresentasikan besarnya jumlah variance konstruk yang dijelaskan oleh model.

Tabel 6

Hasil Uji Kecocokan Model Struktural

\begin{tabular}{cc}
\hline Variabel Laten & R Square \\
\hline Kinerja Usaha Mikro & \\
Modal Sosial & 0,555 \\
Modal Fisik & \\
Modal Sumber Daya Manusia & \\
\hline
\end{tabular}

Nilai $R$-Square sebesar 0,555 yang berarti model termasuk dalam kategori moderate (sedang).

Tabel 7

Hasil Kecocokan Model Struktural

\begin{tabular}{c|c|c|c|c}
\hline \multirow{2}{*}{ Hipotesis } & Path & $\begin{array}{c}\text { Total } \\
\text { Effects }\end{array}$ & $\begin{array}{c}\text { T-statistics } \geq \\
1,96\end{array}$ & Kesimpulan \\
\hline $\mathrm{H} 1$ & $\mathrm{MSDM} \longrightarrow \mathrm{KUM}$ & 0,493 & 3,151 & Signifikan \\
$\mathrm{H} 2$ & $\mathrm{MF} \rightarrow \mathrm{KUM}$ & 0,350 & 0,342 & Tidak Signifikan \\
$\mathrm{H} 3$ & $\mathrm{MS} \rightarrow \mathrm{KUM}$ & 0,051 & 1,437 & Tidak Signifikan \\
\hline
\end{tabular}

Modal sumber daya manusia (MSDM) memiliki pengaruh positif sebesar 0,493 terhadap kinerja usaha mikro yang ditunjukkan dengan nilai $t$-statistics sebesar 3,151. Sementara modal sosial (MS) dan modal fisik (MF) tidak berpengaruh terhadap kinerja usaha mikro yang ditunjukkan dengan nilai $t$-statistics yang lebih kecil dari $1,96$.

\section{Overall Fit Index (Goodness of Fit)}

Untuk GoF Index dihitung dari akar kuadrat nilai average communality index, dan average R-squares:

$$
\begin{gathered}
\text { GoF }=\sqrt{\text { Com } \times \mathrm{R}^{2}} \\
\begin{aligned}
\text { GoF } & =\sqrt{0,6315 \times 0,139} \\
& =0,30
\end{aligned}
\end{gathered}
$$

Nilai GoF Index yang dihasilkan $0,30<0,36$ maka dapat disimpulkan bahwa GoF dari model penelitian adalah cukup baik. 


\section{Modal Sumber Daya Manusia dan Kinerja Usaha Mikro}

Modal SDM terbukti berpengaruh signifikan sebesar 0,493 terhadap kinerja usaha mikro dengan t-statistics 3,151 > t-tabel 1,96. Hal ini sejalan dengan penelitian Hmieleski and Corbett (2006), Diochon et al. (2008), Cardon et al. (2009), Sandra dan Purwanto (2017), Dewi (2013), Purwaningsih dan Kusuma (2014), Saddam dan Mahfudz (2017). Modal SDM bahkan berdampak signifikan terhadap kinerja ekonomi nasional dan meningkatkan pendapatan rumah tangga (Sitepu et al., 2009). Hasil di atas juga mendukung Teori Resources Based di mana kinerja sebuah perusahaan sangat bergantung pada peran SDM (keterampilan, pengalaman, kreativitas, inovatif, dan pemecahan masalah) dan sumber daya intelektualnya (kualitas produk/brand, patent, dan partnership).

Untuk itu, perusahaan perlu memfokuskan perhatiannya pada upaya pengembangan keterampialn karyawan agar dapat menunjang peningkatan produktivitas usaha mikro. Upaya pengembangan keterampilan karyawan diyakini dapat meningkatkan kinerja usaha dalam jangka panjang (Gonzalez-Uribe and Leatherbee, 2018; Samosir et al., 2016). Ibarat memberikan hadiah kepada seseorang, jika hadiah tersebut adalah barang (fisik) maka seiring berjalannya waktu, nilai barang tersebut akan mengalami penyusutan manfaat. Namun, jika hadiah yang diberikan adalah pendidikan, pelatihan, atau pemberdayaan, maka dalam jangka panjang kualitas penerima hadiah akan semakin meningkat. Demikian halnya dengan usaha mikro. Sektor ini membutuhkan pemberdayaan manusia secara riil, bukan sumbangan dana semata.

\section{Modal Fisik dan Kinerja Usaha Mikro}

Hasil pengujian membuktikan secara empiris bahwa modal fisik tidak berpengaruh signifikan terhadap kinerja usaha mikro dengan nilai t-statistics 0,342 $<\mathrm{t}$ tabel 1,96. Hasil ini mendukung temuan Yuliati (2011) yang menemukan bahwa modal kerja (modal fisik) tidak berpengaruh signifikan terhadap kinerja usaha.

Hasil wawancara dengan beberapa responden menunjukkan bahwa pelaku usaha tidak mengalami kendala yang berarti terkait modal fisik (perlengkapan dan peralatan produksi). Alasannya, perlengkapan dan peralatan produksi tergolong sederhana dan mudah digunakan. Responden sebanyak 26 orang (84\%) mengakui bahwa teknik produksi dan teknik pemasaran yang digunakan masih bersifat manual dan sederhana sehingga tidak membutuhkan mesin, kendaraan, bahkan teknologi yang canggih. Modal yang kecil tidak mendukung para pelaku usaha ini untuk menggunakan teknologi canggih dalam operasional usahanya. Responden lainnya (16\%) mengakui telah menggunakan Go-Jek untuk proses pemasaran produknya.

Pemanfaatan perlengkapan dan peralatan yang sederhana sudah cukup bagi usaha mikro. Peningkatan produktivitas sulit terjadi secara progresif karena operasional usaha masih bersifat sederhana. Selain itu, tenaga kerja merupakan masyarakat dengan tingkat pendidikan/keterampilan rendah. Pekerja ini bekerja seadanya pada lapangan usaha yang tidak membutuhkan keterampilan manajerial dan pendidikan tinggi. Tingkat pendidikan pelaku usaha mikro di Kota Manado seperti terlihat pada Gambar 3. 


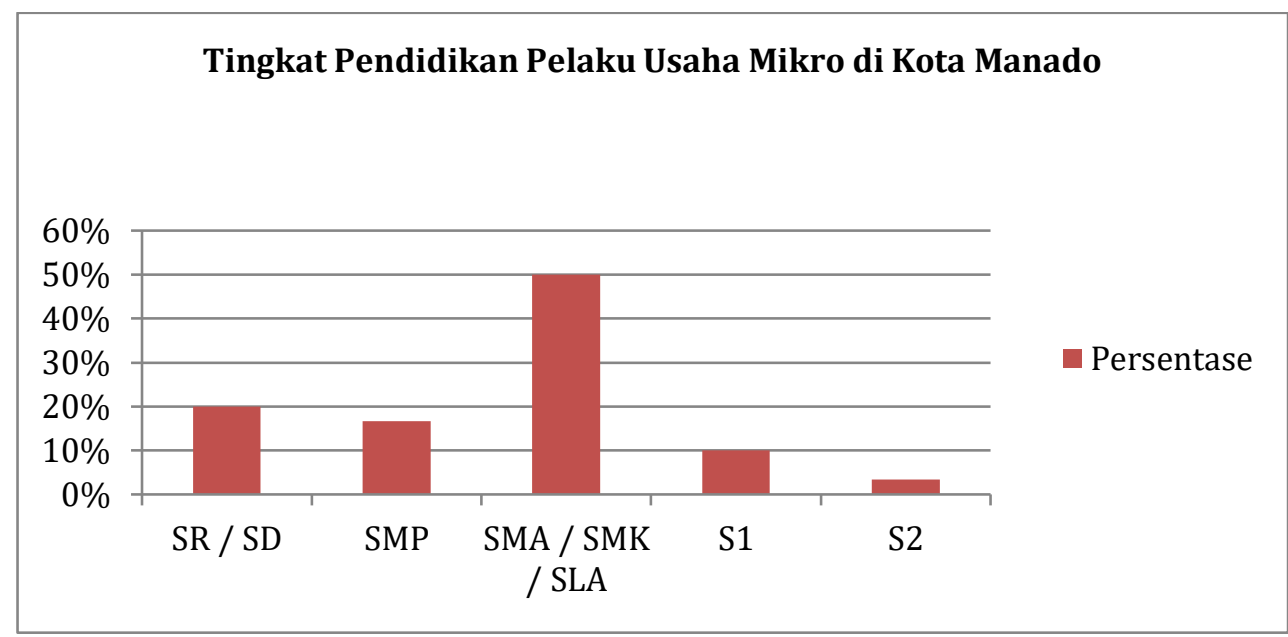

Gambar 3

Tingkat Pendidikan Pelaku Usaha Mikro di Kota Manado

\section{Modal Sosial dan Kinerja Usaha Mikro}

Hasil uji membuktikan secara empiris bahwa modal sosial tidak berpengaruh signifikan terhadap kinerja usaha mikro dengan nilai t-statistics $1,437<\mathrm{t}$ tabel 1,96. Hasil ini senada dengan temuan Prasetyo dan Harjanti (2013) dan Primadona dan Emrizal (2017). Hasil observasi dan wawancara juga mendukung hasil pengujian di atas, di mana 50\% responden menyatakan tidak mengenal pelanggannya. Ini menunjukkan bahwa kinerja usaha ini tidak terpengaruh oleh kedekatan pelaku usaha dengan pelanggan. Selain itu, area usaha mikro yang terletak di pusat kota (khayalak ramai) tidak banyak memberikan ruang interaksi bagi pelaku usaha dan konsumennya. Di samping itu, sebagian besar pelaku usaha (94\% responden) mengakui tidak pernah menerima kredit usaha dari bank sehingga tidak ada interaksi antara pelaku usaha dengan perbankan.

Interaksi sosial yang dibangun dengan lingkungan saja tidak cukup untuk meningkatkan kinerja usaha mikro. Mengingat kembali bahwa Indonesia sangat kental dengan budaya saling menghargai dan menghormati, maka interaksi sosial sudah dianggap sebagai suatu keharusan bagi setiap masyarakat termasuk di dalamnya pelaku usaha. Interaksi yang dibangun dengan lingkungan sekitar bukanlah untuk mendapatkan laba, tetapi karena kebutuhan dasar pelaku usaha yaitu bersosialisasi dengan lingkungan sekitar.

\section{SIMPULAN}

Modal SDM terbukti merupakan ujung tombak bagi peningkatan kinerja usaha mikro dalam jangak pendek maupun jangka panjang. Kemandirian usaha mikro yang dikombinasikan dengan SDM yang terdidik, terampil, berkarakter baik dapat menunjang pergeseran kinerja usaha mikro menuju level industri kecil dan menengah. Selain itu, modal fisik tidak berdampak signifikan pada kinerja usaha mikro. Hal ini disebabkan oleh karena modal fisik yang digunakan oleh usaha mikro cenderung sederhana sehingga tidak menujang peningkatan kinerja (produktivitas) 
yang progresif. Sudah saatnya industri mikro diberdayakan dan dikembangkan secara serius, harmonis, dan santun.

Demikian halnya dengan modal sosial yang tidak akan cukup untuk meningkatkan kinerja usaha mikro. Interaksi dan kepercayaan yang terbangun terkadang menjadi jalur munculnya hutang usaha yang berdampak bagi lambatnya pertumbuhan usaha mikro. Untuk itu, pelaku usaha mikro perlu dilatih untuk melakukan pencatatan terhadap setiap transaksi, teristimewa hutang sehingga dapat menunjang keberlanjutan usaha dan peningkatan kinerja usaha dalam jangka panjang.

\section{SARAN}

Keterbatasan dalam penelitian ini adalah kecilnya sampel yang diambil karena hanya berfokus pada usaha mikro di Kecamatan Wenang (pusat perkotaan). Untuk itu, penelitian mendatang disarankan memperluas sampel penelitian dan bidang usaha yang ditekuni agar hasil penelitian lebih representatif terhadap semua bidang usaha sektor mikro di kota Manado.

\section{DAFTAR PUSTAKA}

Analia, Devi, Yusman Syaukat, Akhmad Fauzi, dan Ernan Rustiadi, 2019, Modal sosial (Network) Upaya Meningkatkan Kinerja Usaha Mikro, Kecil (UMK) di Kota Padang, Sumatera Barat, Jurnal Ekonomi Pertanian, dan Agribisnis (JEPA), Vol. 3, No. (1), hal. 108-117.

Barney, J., 2001, Year Retrospective on the Resource-Based View, Journal of Management, Vol. 27, page 643-650, https://doi.org/10.1177/0149206301 02700602 .

Bidang Neraca Wilayah dan Analis Statistik, 2016, Potensi Usaha Mikro Kecil Provinsi Sulawesi Utara Sensus Ekonomi, Badan Pusat Statistik Provinsi Sulawesi Utara.

Binarto, R., 2013, Analisa Modal Sosial dan Entrepreneurial Leadership Pengusaha Mikro dan Kecil Di Jawa Timur, Agora, Vol. 1, No. 3, hal. 14511458 .

Cardon, M. S., J. Wincent, J. Singh, and M. Drnovsek, 2009, The Nature and Experience of Entrepreneurial Passion, Academy of Management Review, Vol. 34, No. 3, page 511-532, https://doi.org/10.5465/AMR.2009.40633190.

Chittithaworn, C., A. Islam, T. Keawchana, and D. H. M. Yusuf, 2011, Factors Affecting Business Success of Small \& Medium Enterprises (SMEs) in Thailand, Asian Social Science, Vol. 7, No. 5, page 180-190, https://doi.org/10.55 39/ ass.v7n5p180.

De Oliveira, J. F., 2013, The Influence of The Social Capital on Busniness Performance: An Analysis in The Context of Horizontal Business Networks, Revista de Administracao Mackenzie, 6776, page 209-235, https://doi. org/10.1590/E-mail. 
Dewi, R. S., 2013, Pengaruh Faktor Modal Psikologis, Karakteristik Entrepreneur, Inovasi, Manajemen Sumber Daya Manusia, dan Karakteristik UKM Terhadap Perkembangan Usaha Pedagang di Pasar Tradisional (Studi Kasus pada Pedagang Sembako, dan Snack di Pasar Peterongan), Jurnal Administrasi Bisnis, Vol. 2, No. 1, hal. 29-40, https://doi.org/10.14710/jab.v2i1.5352.

Diochon, M., T. V. Menzies, and Y. Gasse, 2008, Exploring the Nature and Impact of Gestation-Specific Human Capital Among Nascent Entrepreneurs, Journal of Developmental Entrepreneurship, Vol. 13, No. 2, page 151-165.

Fornell, C. and D. F. Larcker, 1981, Structural Equation Models with Unobservable Variables and Measurement Error: Algebra and Statistics, Journal of Marketing Research, Vol. 18, No. 3, https://doi.org/10.2307/3150980.

Ghozali, Imam dan Fuad, 2008, Structural Equation Modeling, Universitas Diponegoro, Semarang.

Gonzalez-Uribe, J. and M. Leatherbee, 2018, The effects of business accelerators on venture performance: Evidence from start-Up Chile, Review of Financial Studies, Vol. 31, No. 4, page 1566-1603, https://doi.org/10.1093/rfs/hhx103.

Grant, R. M., 1991, The Resource-Based Theory of Competitive Advantage: Implications for Strategy Formulation, page 114-135.

Hasan, Norhafizah Abu and Nor Liza Abdullah, 2018, Relationship between intellectual capital and innovative capabilities: Evidence from Malaysian SMEs, International Journal of Business and Management Science, Vol. 8, No. 2, page 439-460.

Hmieleski, K. M. and A. C. Corbett, 2006, Proclivity for Improvisation as a Predictor of Entrepreneurial Intentions, Journal of Small Business Management, Vol. 44, No. 1, page 45-63, https://doi.org/10.1111/j.1540627X.2006.00153.x.

Imran, M. and Z. Jian, 2018, Social Media Orientation and SME Export Performance: A Conceptual Framework, International Journal of Management, Accounting \& Economics, Vol. 5, No. 6, page 473-481, https://search.ebsco host.com/login.Aspx? direct=true \&db=bth\&AN=130958424\&site=ehost-live.

Latan, H. dan Imam Ghozali, 2012, Konsep, Teknik, dan Aplikasi SmartPLS 2.0 M3 untuk Penelitian Empiris, Badan Penerbit Universitas Diponegoro, Semarang.

Mahesa, A. A. N. G., N. D. Setiawana, dan I. A. N. Saskara, 2016, Analisis FaktorFaktor yang Mempengaruhi Pendapatan UKM Sektor Perdagangan di Kota Denpasar, E-Jurnal Ekonomi, dan Bisnis Universitas Udayana.

Pierre, A. T., 2017, Local Small Business Development in two Swedish Northern Rural Areas - A Matter of Synergy, Social Capital, and Trust? Journal of Rural \& Community Development, Vol. 12, 2/3, page 143-167, http://search. 
ebscohost.com/login.aspx direct $=$ true $\& \mathrm{db}=\mathrm{a} 9 \mathrm{~h} \& \mathrm{AN}=127839466 \&$ site $=$ eds-li ve.

Prasetyo, T. dan D. Harjanti, 2013, Modal Sosial Pengusaha Mikro, dan Kecil Sektor Informal, dan Hubungannya dengan Kinerja Bisnis di Wilayah Jawa Timur, Agora, Vol. 1, No. 3, hal. 1-4, http://publication.petra.ac.id/index. $\mathrm{php} / \mathrm{manajemen-bisnis/article/view/1146.}$

Primadona dan Emrizal, 2017, Pengaruh Modal Sosial Terhadap Produktivitas Petani, Polibisnis, Vol. 9 (1987), hal. 89-97.

Purwaningsih, R. dan P. Kusuma, 2015, Analisis Faktor-Faktor yang Mempengaruhi Kinerja Usaha Kecil, dan Menengah (UKM) dengan Metode Structural Equation Modeling (Studi Kasus UKM Berbasis Industri Kreatif Kota Semarang), Prosiding SNST Ke-6, 2011, hal. 17-22.

Ramaseshan, B., L. S. C. Yip, and J. H. Pae, 2006, Power, Satisfaction, and Relationship Commitment in Chinese Store-Tenant Relationship, and Their Impact on Performance, Journal of Retailing, Vol. 82, No. 1, page 63-70, https://doi.org/10.1016/j.jretai.2005.11.004.

Saddam, F. M. dan Mahfudz, 2017, Pengaruh Modal Manusia, Modal Struktural, Modal Relasional Terhadap Kapabilitas Inovasi, dan Efisiensi Operasional Modal, serta Implikasinya Terhadap Kinerja Bisnis, Diponegoro Journal of Management, Vol. 6, No. 4, hal. 1-12.

Sáez, P. Z., E. C. Cortés, and H. M. Manchón, 2006, Human Capital Intangibles in Family Firms: Identification and Measurement, Proceedings of the International Conference on Intellectual Capital, Knowledge Management \& Organizational Learning, page 477-485.

Samosir, M. S., M. S. Utama, dan A. A. I. N. Marhaeni, 2016, Analisis Pengaruh Pemberdayaan, dan Kinerja UMKM Terhadap Kesejahteraan Pelaku UMKM di Kabupaten Sikka - NTT. E-Jurnal Ekonomi, dan Bisnis Universitas Udayana, Vol. 5, hal. 1359-1384.

Sandra, A. dan E. Purwanto, 2017, Pengaruh Faktor-Faktor Eksternal, dan Internal Terhadap Kinerja Usaha Kecil, dan Menengah di Jakarta, Business Management Journal, Vol. 11, No. 1, https://doi.org/10.30813/bmj.v11i1.623.

Santoso, I., D. Yuwandini, and S. A. Mustaniroh, 2015, Pengaruh Kredit, dan Sumber Daya Manusia Terhadap Kinerja UMKM Agroindustri dengan Pemasaran sebagai Variabel Antara, Jurnal Manajemen, dan Agribisnis, Vol. 12, No. 3, hal. 174-182, https://doi.org/10.17358/jma.12.3.174.

Schenkel, M. T., R. R. D’Souza, and C. H. Matthews, 2012, Entrepreneurial Capital: Examining Linkages in Human and Social Capital of New Ventures, Journal of Developmental Entrepreneurship, Vol. 17, No. 2, page 1-26, https://doi.org/10.1142/S1084946712500094. 
Setyawan, A., I. Susila, dan S. Anindita, 2019, Influence of Power Asymmetry, Commitment, and Trust on SME Retailers' Performance, Business: Theory and Practice, Vol. 20, hal. 216-223. https://doi.org/10.3846/btp.2019.21.

Singh, R. P., G. E. Hills, G. T. Lumpkin, and R. C. Hybels, 1999, The Entrepreneurial Opportunity Recognition Process: Examining The Role of SelfPerceived Alertness, and Social Networks, Academy of Management Proceedings, Vol. 1, G1-G6, https://doi.org/10.5465/apbpp.1999.27600505.

Sitepu, Rasidin Karo Karo, Bonar M. Sinaga, Rina Oktaviani, dan M. Tambunan, 2009, The Impact of Human Capital Investment on Income Distribution and Poverty Incidence in Indonesia, Forum Pascasarjana, Vol. 32, No. 2, hal. 117 127.

Sjafii, A., 2004, Pengaruh Investasi Fisik, dan Investasi Pembangunan Manusia, Journal of Indonesian Applied Economics, Vol. 3, hal. 59-76.

Steiner, Bodo and Cong Wang, 2016, Social Capital, Religius Affiliation and Business Performance in Denmark, Academy of Management Annual Meeting Proceedings.

Suriatna, D. dan R. R. R. Ardianti, 2013, Analisa Modal Sosial, dan Entrepreneurial Leadership Pengusaha Mikro, dan Kecil di Jawa Timur, Agora, Vol. 1, No. 3, hal. 1451-1458.

Tenenhaus, M., S. Amato, E. V. Vinzi, 2004, A Global Goodness-of-Fit Index for PLS Structural Equation Modelling, The XLII SIS Scientific Meeting, page 739742.

Thobias, E., A. Tungka, and J. Rogahang, 2013, Pengaruh Modal Sosial Terhadap Perilaku Kewirausahaan (Studi Kasus pada Pelaku Usaha Mikro, Kecil, Menengah, di Kecamatan Kabaruan, Kabupaten Kepulauan Talaud), Journal Acta Diurna, hal. 1-23.

Wauran, Patrick C., 2012, Strategi Pemberdayaan Sektor Informal Perkotaan di Kota Manado, Jurnal Pembangunan Ekonomi, dan Keuangan Daerah (PEKD), Vol. 7, No. 3, hal. 1-30.

Wilantara, Rio dan Susilawati, 2016, Strategi, dan Kebijakan Pengembangan $U M K M$, PT Refika Aditama, Bandung.

Worokinasih, S. and W. Potipiroon, 2019, Microfinance Repayment Performance of SMEs in Indonesia: Examining The Roles of Social Capital, and Loan Credit Terms, Journal of Behavioral Science, Vol. 14, No. 1, page 28-45.

Wu, I. L. and J. L. Chen, 2014, Knowledge Management Driven Firm Performance: The roles of Business Process Capabilities, and Organizational Learning, Journal of Knowledge Management, Vol. 18, No. 6, page 1141-1164, https://doi.org/10.1108/JKM-05-2014-0192. 
Determinan Kinerja Usaha Mikro (Studi pada Vsaha Mikro di Kecamatan Wenang, Manado)

Yuliati, N. W., 2011, Pengaruh Kebijakan Modal Kerja Terhadap Profitabilitas pada Perusahaan Hotel, dan Restoran di Bursa Efek Indonesia, E-Jurnal Ekonomi Dan Bisnis Universitas Udayana, hal. 709-723. 